\title{
La reaparición de Alicia Partnoy: Historia del exilio de una sobreviviente de los espacios de detención clandestina de la última dictadura en Argentina (1976-1983)
}

\section{The reappearance of Alicia Partnoy: History of a survivor exile from clandestine detention spaces during the last dictatorship in Argentina (1976-1983)}

\author{
Cristian Rama \\ Universidad Nacional de Avellaneda \\ Universidad de Buenos Aires \\ Consejo Nacional de Investigaciones Científicas y Técnicas \\ cristiannrama@gmail.com
}

(Argentina)

A través del estudio de caso del exilio de Alicia Partnoy en los Estados Unidos (1979-1983), el presente artículo propone examinar distintas problemáticas en torno a las condiciones de posibilidad para las actividades de denuncia pública de sobrevivientes de espacios de detención clandestina durante la última dictadura argentina (1976-1983) y luego exilados en un contexto de intenso activismo en las redes trasnacionales de derechos humanos (1979-1981). Se pretende observar la importancia de las estructuras de inserción social y política en el exilio, y la construcción de tramas vinculares en clave humanitaria como vías para una exposición pública legitimada. Se analizará así el desarrollo de distintas prácticas políticas llevadas a cabo por Alicia y la centralidad que adquirió en ellas la historia vivida recientemente en sus detenciones durante el gobierno de facto. También, se abordará la manera en la que el contexto de producción de esa militancia tuvo injerencia en su recomposición subjetiva e identitaria. Finalmente, el recorrido por su trayectoria permitirá examinar algunas de las vicisitudes en el proceso de construcción de la "legitimidad" de la palabra del/la sobreviviente en el exilio.

Palabras Clave: sobrevivientes, exilios, Derechos Humanos, Alicia Partnoy. 


\begin{abstract}
Through the case study of Alicia Partnoy' exile in the United States (1979-1983), this article examines different problems related to public denunciations of survivors of clandestine detention during the last Argentine dictatorship (1976-1983) (who later exiled) in a context of intense activism in transnational human rights networks (1979-1981). The aim is to observe the importance of the structures of social and political insertion in exile and the bond building in a humanitarian key in order to achieve a legitimated public exposure. In addition, the article analyzes the development of different political practices carried out by Alicia and the centrality of her detention experience in Argentina during the de facto government. Also, it is intended to address the way in which the context of production of that militancy influenced her subjective and identity reinstating. Finally, the analysis of her history allows to examine some vicissitudes in the building of the "legitimacy" of the testimony of the clandestine detention center survivor in exile.
\end{abstract}

Keywords: survivors, exiles, Human rights, Alicia Partnoy.

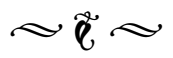

\section{Introducción}

En el exilio argentino durante el último periodo dictatorial (1976-1983) algunos/as sobrevivientes de los centros clandestinos de detención (en adelante, CCD) encontraron condiciones de posibilidad para la escucha pública y para ejercer la denuncia de lo que habían padecido recientemente. El activismo y las voces de estas víctimas resultaron clave en la lucha transnacional contra el régimen de facto (CADHU/Comisión Argentina de Derechos Humanos, 2014 [1977). ${ }^{1}$

1. También ver: Comisión Argentina de Derechos Humanos (octubre 1979). Testimonio de sobrevivientes del Genocidio en Argentina. Recuperado de http:// eltopoblindado.com/documentos/?tags=ccdye; Comisión Argentina de Derechos Humanos (1980). Informe del campo de concentración y exterminio "La Perla”. Recuperado de http://eltopoblindado.com/ documentos/?tags=ccdye
Esto no significó que en los países de tránsito o de inserción no experimentaran dificultades para el habla y para la escucha de sus historias, de hecho muchos/as sobrevivientes de CCD decidieron mantenerse al margen y no realizar un testimonio público de lo que les ocurrió. Las desconfianzas, las desmoralizaciones, las reinterpretaciones del momento político a nivel individual y/o de los grupos de pertenencia, miedos, persecuciones, el hostigamiento por parte de miembros de los grupos de tareas, y conflictos con distintos espacios políticos, fueron algunas de las causas. En relación a esto último, la historiadora Marina Franco (2008) ha resaltado la existencia de tensiones desde algunos colectivos de exiliados/as en Francia con sobrevivientes de CCD, sobre todo con aquellos/as que hicieron público un testimonio en el que asumieron la muerte de los/as desaparecidos/as. La autora menciona que luego de la conferencia de prensa de las "tres sobre- 
vivientes de la Escuela de Mecánica de la Armada" (en adelante ESMA) en París, en 1979, se produjo una crisis de tal magnitud que pudo tener que ver con el silenciamiento de otros/as que habían sobrevivido a los CCD; esta concepción llevó a algunos/as exiliados/as hasta la sospecha de que los/as sobrevivientes hablaban por los militares (Franco, 2008, pp. 157-158). ${ }^{2}$

El objetivo principal que se propone el presente artículo es el de indagar sobre distintas problemáticas en torno a las condiciones de posibilidad del ejercicio de la denuncia de las/ os sobrevivientes de los espacios de detención clandestina en el exilio en un contexto de intenso activismo en las redes trasnacionales de derechos humanos (1979-1981). Una de las ideas que se trabajará es que gran parte de los matices en esas heterogéneas historias tuvieron que ver con el estado subjetivo de las víctimas, el de las estructuras relacionales en dónde estas mismas se insertaron, y el contexto en el que se dio esa producción. ${ }^{3}$ En este sentido, desde un

2. Las sobrevivientes fueron Alicia Milia de Pirles, Ana María Martí y Sara Solarz de Osatinsky, todas militaban en Montoneros y compartieron la desaparición y el cautiverio en el CCD de la ESMA. El testimonio tuvo una composición colectiva, que involucró a otras víctimas $\mathrm{y}$ militantes, $\mathrm{y}$ fue dado en una conferencia de prensa ante la Asamblea Nacional Francesa, el 12 de octubre de 1979. Al año siguiente sería publicado por la CADHU.

También, ver Ayala (2013). En esta ponencia, a través de los testimonios de distintos/as sobrevivientes de la ESMA, que pertenecían a Montoneros, relata cómo en Venezuela sufrieron las sospechas de colaboración por parte de referentes de la organización, lo que llevó a varios de ellos/as a alejarse por un tiempo o definitivamente.

3. El historiador Rodrigo González Tizón (2018) destaca la heterogeneidad de experiencias de denuncia en el exilio realizadas por sobrevivientes de CCD. No obstante también señala que éstas compartieron contextos de producción y enunciación comunes, y determinadas características formales y de contenido que permiten pensar en "circuitos testimoniales" (p. 127). estudio de caso, el del exilio de Alicia Partnoy ${ }^{4}$ en los Estados Unidos (1979-1983), se pretende observar la importancia de las estructuras de inserción social y política, y la construcción de tramas vinculares en torno a la denuncia en clave humanitaria contra el gobierno de facto. También, se indagará en la centralidad que tuvieron estos marcos de inserción y el accionar político de la víctima para su recomposición subjetiva e identitaria. Finalmente, el recorrido por su trayectoria permitirá examinar algunas de las vicisitudes en el proceso de construcción de la "legitimidad" de la palabra del/la sobreviviente de CCD en el exilio.

Se parte de una concepción similar a la que plantea la antropóloga Luciana Messina (2012), en cuanto a que la posición de testigo no se deriva de haber vivido determinado acontecimiento ni del hecho de dar testimonio, sino que este se constituye en y a través de las mismas prácticas que se articulan en torno a la producción testimonial:

Más que un ser testigo hay un devenir testigo como el resultado de la articulación entre una serie de prácticas que los sujetos llevan adelante y ciertas condiciones sociales y políticas que habilitan (o inhiben) la producción y circulación de los testimonios (p. 56).

En el análisis de la biografía de Alicia es posible observar cómo en el exilio en los Estados Unidos esta protagonista encontró condicio-

4. Alicia Partnoy es una reconocida intelectual y activista humanitaria. Ha sido caso en varios de los juicios realizados por los crímenes cometidos por la última dictadura en lo que fue la Zona V. Una de sus producciones literarias más reconocida es La Escuelita (2006 [1986]), escrita en gran parte durante 1983. Participó, entre otros espacios relacionados a los derechos humanos, en el directorio de Amnistía Internacional durante los años '90. Actualmente trabaja en la Universidad de Loyola, en California. 
nes de posibilidad para llevar adelante una intensa actividad militante en contra de la última dictadura en la que fue fundamental su propia historia como víctima de la represión. La hipótesis sobre la que se trabaja es que en el exilio en ese país Alicia logró insertarse en espacios en los que se la reconoció en su condición de víctima y donde resultó legitimada su palabra. En esto fue clave el contexto en el que se produjo esa militancia, interactuando con sectores de una sociedad relativamente sensibilizada y con organizaciones del exilio argentino que, entre los años 1979-1981, comenzaban a delinear posibles vías para sancionar al régimen de facto por las violaciones a los derechos humanos (Jensen, 2017). En estas inscripciones, en las que la práctica testimonial se volvió nodal, Alicia fue conformando un discurso desde el que se identificó -y fue identificada- como testigo y sobreviviente.

Si bien en los últimos quince años los estudios sobre la Historia Reciente ${ }^{5}$ y el campo de los Exilios Políticos han experimentado un proceso de expansión y consolidación, en los que los análisis de las problemáticas y trayectorias de las víctimas directas de la represión no han sido ajenos, aún se presentan muchos interrogantes y desafíos por abordar. ${ }^{6}$ En este sentido, y quizás por la exposición de las/os sobrevivientes de CCD en los estrados judiciales ante la nueva etapa de juicios en Argentina, desde mediados de la década pasada se han generado

\footnotetext{
5. Al momento se han realizado varios estudios historiográficos acerca de la expansión y -en los últimos años- consolidación del campo de la Historia Reciente. Véase: Franco y Lvovich (2017); Águila, Luciani, Seminara y Viano (2018).

6. Sobre el intenso desarrollo del área de estudios de los Exilios Políticos también se han producido algunas reflexiones historiográficas, por ejemplo: Jensen y Lastra (2016); Jensen (2018).
}

importantes líneas de investigación sobre estas personas como actores políticos y sociales con sus propias problemáticas, incluso con el desarrollo tesis de doctorado (Lampasona, 2017; González Tizón, 2018). Este artículo pretende ser un aporte a estas áreas de estudio en un tema con relativa vacancia desde la historiografía, el de las primeras apariciones públicas de estas personas en el exilio y la construcción de la figura del/la "sobreviviente" (González Tizón, 2016).

El trabajo estará estructurado en cuatro partes. En la primera, se expondrán cuestiones biográficas sobre Alicia antes de partir al exilio. En la segunda, se abordará su llegada a Seattle y se examinarán las estructuras sociales, políticas, económicas y culturales que permitieron su inserción. En la tercera, se analizará la importancia de la relación habla y escucha en esos primeros tiempos en la ciudad del norte y cómo esos factores fueron clave en el posicionamiento identitario. Finalmente, se trabajará sobre el viaje y el asentamiento en Washington, para pensar las claves que estuvieron en la composición de la denuncia en esa ciudad.

Con respecto a las fuentes, se ha tenido acceso a distintos periódicos de la época, tanto de Estados Unidos como de México, estos aportan valiosa información sobre el contexto de inserción en el exilio. También, se pudo tomar contacto con dos declaraciones testimoniales -en distintos formatos narrativos- escritas en el año 1981 por Alicia Partnoy: una denuncia enviada en abril de ese año a organizaciones humanitarias y una carta dirigida a los padres de un compañero desaparecido. A través de estos testimonios es posible acceder a distintos elementos del marco de producción de los mismos. Por último, entre los años 2016 y 2018 se han realizado entrevistas personales 
con algunos/as de los/as protagonistas de esta historia en las que se abordó la etapa del exilio.

\section{Alicia en el país}

Alicia Partnoy nació en Bahía Blanca el 7 de febrero de 1955. Se crió en una familia de clase media, junto a su mamá, su papá y su hermano Daniel. Luego de terminar el colegio secundario, comenzó a estudiar Letras en la Universidad Nacional del Sur (en adelante, UNS), carrera que inició en el año 1973. El 19 de septiembre de 1974 se casó con Carlos, juntos tuvieron una hija llamada Ruth Irupé, nacida el 28 de junio del año siguiente.

Aunque había sido delegada de curso y tenía contactos con compañeros/as de la Juventud Universitaria Peronista (en adelante, JUP), Alicia comenzó a militar en forma más activa luego del golpe de 1976. Dentro de la estructura de la organización participaba también su compañero, Carlos, algunos/as amigos/as y varios/as conocidos/as que entre los años 1976 y 1977 serían desaparecidos/as y asesinados/as.

El 12 de enero del 1977, Alicia fue secuestrada en su casa, donde estaba con Ruth. La niña quedó abandonada unas horas, siendo rescatada por sus abuelos maternos. En forma simultánea detuvieron a Carlos en su lugar de trabajo. Ambos/as fueron llevados/as al CCD conocido como la "Escuelita", ${ }^{7}$ permaneciendo en ese lugar hasta el 25 de abril. En esos tres meses, vivieron todo tipo de formas de desestructuración: la pérdida sensorial, las sesiones

7. La "Escuelita" se denominó a uno de los CCD más grandes que funcionó en la Sub-Zona V1 que comprendía las localidades del sur de la Provincia de Buenos Aires y del noreste de Río Negro. El CCD estuvo activo durante 1976 y 1978 en terrenos del V Cuerpo, sobre el camino de la Carrindanga, en Bahía Blanca. de tortura, la mala alimentación e higiene, la imposibilidad de moverse, la prohibición de comunicarse, los continuos golpes, el acoso sexual y las constantes amenazas. Allí compartieron el cautiverio con compañeros/as y amigos/as, algunos/as de ellos/as fueron asesinados/as en "enfrentamientos" fraguados por el propio aparato represor y otros/as continúan desaparecidos/as. A pesar de haber sido llevados/as de la "Escuelita" a la Unidad Penitenciaria No 4 de Villa Floresta, en Bahía Blanca, continuaron desaparecidos/as por cincuenta y dos días más en celdas de aislamiento. El 17 de junio del 1977 Alicia logró reencontrarse con sus padres y Ruth en la cárcel. En ese momento pudo recién saber, luego de cinco meses de incertidumbre, qué había ocurrido con su hija y también enterarse de que Carlos estaba detenido en la misma unidad. El 22 de agosto éste último fue trasladado a la Unidad No 6 de Rawson (Provincia de Chubut), mientras que ella, el 8 de octubre, fue transferida al penal de Villa Devoto (Ciudad de Buenos Aires).

La cárcel fue otro dispositivo de desestructuración. Allí recibieron por parte del personal de los servicios penitenciarios y de las Fuerzas Armadas distintas formas de ataques a la subjetividad (D'Antonio, 2017). No obstante, también fue un ámbito de resistencias -al igual que lo fue la "Escuelita"-, en el que las prácticas colectivas cumplieron un rol fundamental. Como en otros casos de sobrevivientes que fueron legalizados/as, la situación de "blanqueo" pudo servir como un primer espacio de socialización de lo ocurrido en los CCD, encontrando allí contención y escucha.

En la cárcel también pudo comenzar a escribir. Por ejemplo, en la celda de aislamiento en la que pasó los primeros cincuenta y dos días, consiguió un lápiz y un papel y se dedi- 
có a transcribir de memoria todos los poemas que había producido hasta ese entonces. Ese trabajo memorístico le sirvió para afrontar la desestructuración del aislamiento. A lo largo de su detención en la Unidad 4 y en Devoto, a través de la poesía fue expresando ciertas cuestiones que tenían que ver con lo vivido recientemente. En el mismo sentido, comenzó a ser reconocida entre sus compañeras por sus textos, por lo que le solicitaban que escribiera en determinadas situaciones. En su libro Venganza de la Manzana, resalta la importancia que tuvo la escritura y sobre todo la poesía durante esos días como prisionera: "Mientras tanto, la poesía le ayuda a sobrevivir y a darles ánimo a sus amigas" (Partnoy, 2009, p. 13).

Luego de casi tres años de detención, Carlos el 22 de octubre y Alicia el 23 de diciembre del 1979, lograron salir del país con “opción”. Este derecho, "la opción", fue restringido y aplicado por el gobierno dictatorial en forma discrecional. Como exponen las historiadoras Silvina Jensen y Soledad Lastra (2016), si bien lo que sobreabundó fueron los exilios de hecho, clandestinos y a "cuentagotas", la dictadura "utilizó el derecho a controlar el movimiento de la población como mecanismo coactivo" (p. 166). En un principio el gobierno de facto continuó con las restricciones que había impuesto la presidenta María Estela Martínez de Perón, quien desde noviembre del 1974 accionó una serie de leyes y decretos para limitar las posibilidades de su uso. Consumado el golpe de Estado, los militares suspendieron el artículo 23, que era el que daba la posibilidad de que cualquier detenido/a que estuviera sin causa y a disposición del Poder Ejecutivo Nacional (en adelante, $\mathrm{PEN}$ ), pudiera salir en libertad hacia otro territorio fuera del país. Ante las presiones internacionales, sobre todo desde 1979 , en el contexto de la visita ejercida por la Comi- sión Interamericana de Derechos Humanos (Jensen, 2010; D'Antonio, 2010), fueron otorgando la opción a cierta cantidad de presas/os políticas/os. Luego de muchas gestiones, Alicia y Carlos pudieron hacer uso de ella. Alicia había solicitado primero ir a España, pero no se lo permitieron. Entonces, tramitaron la opción a los Estados Unidos, ya que existía un programa de recepción de refugiados ligado a las políticas de defensa de los derechos humanos del presidente James Carter (Partnoy, 2006, p. 13; Calandra, 2006).

Hasta aquí, el breve recorrido por la biografía de Alicia permite un primer acercamiento a las pérdidas, a las rupturas y a los efectos de los distintos dispositivos represivos en sus cuerpos y en sus círculos sociales. También han sido observables las resistencias y las primeras formas de elaboración de lo vivido, sobre todo la importancia que tuvo la socialización de las experiencias, la poesía y el reconocimiento de sus compañeras. ${ }^{8}$ El exilio significó otra forma de desestructuración para la sobreviviente, el desarraigo produjo nuevos efectos y profundizó otros. ${ }^{9}$ Sin embargo, como se verá a continuación, también permitió condiciones para

8. Sobre la importancia de la socialización de las experiencias para la elaboración de lo vivido hay una abundante bibliografía. Desde los primeros trabajos del Equipo de Acompañamiento a Madres (Kordon y Edelman, 1986) a investigaciones recientes de tesis doctoral, como por ejemplo las de la socióloga Julieta Lampasona (2017), quien realiza un abordaje sobre las distintas formas de elaboración de las y los sobrevivientes de CCD, entre ellas el decirse con otros.

9. Por ejemplo, tuvieron que rearmar el vínculo con Ruth y la relación de pareja con Carlos terminó en una separación al poco tiempo de llegar a Estados Unidos. Por otro lado, la prohibición a que regresara a la Argentina impuesta por el gobierno de ese país le impidió concurrir al funeral de su hermano y visitar a sus padres en 1982. 
resistir y luchar contra la dictadura y para elaborar la experiencia reciente.

\section{Alicia en el exilio, Seattle}

En Seattle vivían alrededor de veinte argentinos, que fueron llegando entre agosto del 1979 y enero del año siguiente, la mayoría también en calidad de refugiados. ${ }^{10} \mathrm{Al}$ arribar a la ciudad Alicia fue recibida por este grupo de compañeros/as, con los que conformaría el Comité de Solidaridad con el Pueblo Argentino (en adelante, COSPAR). También, se acercaron a ella representantes de las congregaciones religiosas que organizaban el South American Refugee Program (en adelante, SARP) ${ }^{11}$

Clave a la hora de pensar las inserciones en aquel país, este grupo de exiliados/as contó con apoyos de las comunidades religiosas de la ciudad, protestantes, católicas y judías. La historiadora Benedetta Calandra (2006), en su libro L'America della solidarietá, expone la importancia que tuvieron distintos sectores no estatales en los Estados Unidos para el desarrollo de redes de solidaridad y para la difusión de las violaciones a los derechos humanos ocurridas en los países de América Latina. En este sentido, remarca que las iglesias fueron factores de presión, ya que pusieron en función el poder lobby de sus estructuras ante importantes actores e instituciones del Estado, pudiendo conseguir así apoyos políticos y recursos.

El trabajo de las iglesias había tenido un gran desarrollo con los refugiados chilenos. Comenzaron a hacerlo luego del golpe de Estado con-

10. El gobierno de Carter les dio una visa llamada Hemisferic Parole 500 con la que los aceptaban en Estados Unidos como refugiados políticos.

11. Programa para Refugiados de Sudamérica. tra Salvador Allende, desarrollando programas -como el SARP-, que lograron consolidarse en el 1975. El origen de estas iniciativas se dio en un contexto de descontento generalizado de una gran parte de la población con respecto a distintas políticas llevadas adelante por los gobiernos norteamericanos de esos años, por ejemplo en relación a la guerra en Vietnam, al apoyo y la colaboración con las dictaduras del cono-sur y al Watergate.

En el caso de los argentinos, si bien las ayudas se iniciaron en los años previos, la labor de las iglesias se consolidó durante 1979, en el contexto de presión internacional ya mencionado sobre la dictadura argentina. El gobierno norteamericano otorgó la visa a un grupo de presos/as políticos/as que había tramitado la opción, sin embargo la mayoría de las ayudas provinieron de estos otros sectores -comenzando por la compra del pasaje de avión para el viaje.

Antonio, quien se convertiría con el tiempo en pareja de Alicia, llegó finalizando septiembre de 1979 a Seattle, luego de haber pasado varios años en cárceles de la Argentina. ${ }^{12}$ Fue uno de los tres primeros argentinos en arribar a la ciudad. En el libro de Calandra (2006), aparece parte de un testimonio en el que Antonio relata cómo fueron esos primeros momentos en el país del norte, exponiendo el funcionamiento de las redes solidarias. Menciona allí que fue recibido, al igual que ocurriría luego en el caso de Alicia, por miembros del SARP y por un grupo de exiliados/as.

12. Antonio fue detenido en La Plata en junio de 1975, allí militaba en la JUP/Montoneros. En esa ciudad estudiaba cine. Pasó la mayor parte del encierro en la Unidad No 9 de La Plata y un tiempo en la cárcel de Caseros. Pudo salir del país el 28 de septiembre de 1979 y llegar a Estados Unidos a los pocos días. 
Estas acciones de "bienvenida" pueden ser interpretadas como una forma de primer acercamiento empático. Quienes tomaban contacto con los/as recién llegados/as eran personas que realizaron las gestiones y que iban a ofrecer una estructura de ayudas, en general habían tenido experiencias en política y por ello padecieron procesos represivos -tanto los/as presos/as políticos/as argentinos/as como los/as chilenos/ as-, pudiendo ser percibidos por los/as recién llegados/as como semejantes. Ese acercamiento empático ofrecía confianzas.

Durante las primeras semanas, Antonio vivió en la casa de quien sería su patrocinador, un sacerdote metodista llamado Melvin. ${ }^{13}$ Este religioso había participado en movilizaciones en contra de las guerras en Vietnam y tenía su misma edad, algo que también resultó importante para el desarrollo del vínculo. $\mathrm{El}$ argentino destaca así la importancia de esta persona y de su familia en ese momento, tanto en las ayudas materiales como también en cuestiones simbólicas: "Mi hanno aiutato a cercare lavoro, mi hanno (...) fatto ottenere la tessera sanitaria, mi hanno insegnato (...) che ridere, $i$ soldi, a prendere l'autobus! Veramente simpatici" (Calandra, 2006, pp. 189 y 190) ["Me han ayudado a conseguir trabajo (...) a obtener la libreta sanitaria, me han enseñado (...) qué risa, a usar el dinero, ja tomar el autobús! Realmente agradables"]. ${ }^{14}$

En una de las entrevistas periodísticas que dieron Alicia y Carlos a días de su reencuentro, también se explicita la asistencia recibida por estas instituciones. El 10 de enero de 1980,

13. Los/as refugiados/as tuvieron durante un tiempo un patrocinador ligado al programa SARP que hacía el seguimiento de la inserción.

14. Las traducciones del italiano e inglés fueron realizadas por el autor.

90 en el periódico The Jewish Transcript, el periodista que escribió la nota Argentinian describe anti-Semitism, explicó que la reunión de la familia fue posible por los esfuerzos en conjunto del Departamento de Estado de los Estados Unidos, del Concilio de Iglesias del Gran Seattle, de la Iglesia Saint George y del SARP. Asimismo, detalló cómo estas solidaridades fueron puestas en práctica: "The couple has been set up in a house by Saint Georges Church and is able to live off a small stipend that is attached to the Comprehensive Employment Training act money that pays for Sanabria's English lessons" [La pareja tuvo acceso a una vivienda a través de la Iglesia Saint Georges y a un pequeño estipendio que se adjunta al dinero de la Ley de Capacitación Integral para el Empleo, que paga las lecciones de inglés de Sanabria"]. ${ }^{15}$ En la publicación, entonces, se refleja la importancia de las gestiones realizadas entre organizaciones eclesiásticas y el gobierno nacional.

En esta estructura de apoyos fue muy importante un espacio de calificación profesional que utilizaron los/as exiliados/as en la ciudad, el Centro de la Raza. Allí asistieron a cursos para el aprendizaje del idioma y de distintos oficios. En esa zona estaba asentado un grupo grande de migrantes mexicanos/as, quienes habían encontrado trabajo en el cultivo de algodón, con lo que el centro era bilingüe. En este lugar también funcionó una guardería, allí trabajó Alicia. El empleo resultó importante porque le permitió trabajar y a su vez cuidar a Ruth. Según recuerda fue un ámbito solidario, construido con símbolos que estimularon el sentido de pertenencia: "Entramos con esas solidaridades; vos pensá que la librería del lugar se llamaba 'Venceremos', entrabas y había

15. Argentinian describe anti-Semitism (January 10 1980). Seattle: The Jewish Transcript, p. 12. Archivo personal de Alicia Partnoy. 
fotos del Che Guevara, libros de izquierda latinoamericana, teníamos ese entorno". ${ }^{16} \mathrm{El}$ ambiente mantenía cierta simbología ligada a sus identidades, lo que colaboró con la construcción de los lazos de solidaridad y el sentido de pertenencia.

En síntesis, en la descripción de ambas historias, la de los primeros tiempos de Antonio y la de los de Alicia, Carlos y Ruth, puede observarse cómo lo/as exiliados/as recibieron distintas ayudas que tuvieron un gran significado para esos primeros tiempos en aquel país. Estas solidaridades permitieron reestructurar elementos esenciales en la organización de la vida en el exilio, tanto en lo económico, como en lo social y en lo político. Pero no sólo eso, otro aspecto clave fue que pudieron contar con la tan necesaria contención y escucha, tanto de sus pares, militantes/exiliados, como la de los promotores del SARP, de las iglesias y de otros espacios de la sociedad. Este aspecto fue muy importante para el derrotero de Alicia en el exilio, por lo que será el tema a explorar en el siguiente apartado.

\section{Seattle, denuncia y escucha}

El arribo de Alicia tuvo repercusión en la ciudad. Según recuerda Antonio, ${ }^{17}$ existían temores porque la dictadura había liberado a Carlos en octubre pero no a ella, con lo que los miembros del COSPAR pensaron en la posibilidad de que podía no producirse la excarcelación. De este modo, durante más de un mes hicieron una campaña utilizando los contactos

16. Entrevista a Alicia Partnoy realizada por Cristian Rama, Buenos Aires, mayo de 2016.

17. Entrevista a Antonio Leiva realizada por Cristian Rama (vía Skype), febrero de 2018. que ofrecieron Patrick Taran ${ }^{18}$ y los grupos de chilenos. ${ }^{19}$ Así, se comunicaron con congresistas, referentes religiosos, periodistas y diversos actores sociales. Como factor de presión, también, realizaron una campaña de difusión que fue desde la recolección de firmas y las intervenciones en los sermones en las iglesias hasta publicaciones en la prensa. Para el momento de la llegada de Alicia había tanta gente involucrada que fue todo un acontecimiento.

E1 simbolismo que representaban las rupturas y la re-vinculación de una familia víctima de la represión dictatorial separada durante tres años generó impacto en la sociedad. Además, Alicia tenía un apellido de origen judío, lo que fue utilizado para exponer un carácter antisemita del gobierno de facto. Es decir, apelaron a conceptos clave en la cultura de aquel país: la familia, el hecho de ser víctimas de una dictadura y en el caso de ella, su apellido ligado a la tradición judía (si bien no era practicante). ${ }^{20}$

Esta campaña fue muy importante para el grupo, ya que se convirtió en una de las primeras

18. Patrick Taran fue uno de los referentes para este grupo de exiliados. Creador del SARP, estuvo a cargo del programa desde 1976 hasta 1980.

19. Para el momento de arribo de los argentinos la sociedad de Seattle contaba con una gran circulación de información con respecto a la situación política de algunos de los países de América Latina. Gran parte de esto estuvo relacionado a la militancia de los exiliados chilenos, que habían dado mucha importancia a esa difusión, construyendo estructuras y relaciones junto a las iglesias que también fueron relevantes para los argentinos. Estos últimos, se "nutrieron" de la transmisión de esas experiencias.

20. Sobre la representación de Alicia como víctima judía y el anti-semitismo de la dictadura, véase: Argentinian describe anti-Semitism (January 10 1980). The Jewish Transcript, p. 12. Recuperado del archivo personal de Alicia Partnoy. Para el autor de la nota, este hecho era un agravante, una dictadura antisemita que perseguía judíos. 
acciones políticas realizadas. Con ella generaron muchas de las estrategias de difusión y de construcción de relaciones que continuarían utilizando en el futuro. Pero también lo fue para Alicia, ya que la difusión le dio cierta visibilidad a su historia en la sociedad.

Lograda esa repercusión, el arribo de Alicia y Ruth fue cubierto por varios medios de comunicación. En una de las entrevistas realizadas al llegar, en el periódico Seattle Times, aparecieron mencionados muchos de los conceptos destacados en la campaña por los argentinos: la familia separada, el hecho de haber sido prisioneros/as políticos/as, la condición judía y el anti-semitismo de la dictadura. De hecho, la primera parte de la nota trataba sobre esto. No obstante, luego de que explicitaron sus sensaciones frente al arribo, al encuentro y la necesidad de reconstruir una familia separada por los dispositivos represivos, tanto Alicia como Carlos direccionaron el habla a la denuncia de la metodología de la represión llevada adelante por la dictadura. Alicia hizo mención a que si bien ella estaba feliz por haber salido con vida, aún quedaban muchos/as prisioneros/as políticos/as allá. La nota se reorientaba así de lo emocional del reencuentro a la exposición de la situación de otros/as compañeros/as y a las condiciones de detención que afrontaron. Como recordó en nuestra entrevista: "Ni bien bajé del avión, ya empezó la denuncia”. Lo mismo hizo Carlos, quien primero planteó a los periodistas el hecho que ambos habían sido detenidos/as por razones políticas, para luego hacer mención al secuestro, a la clandestinidad y a las torturas recibidas: ${ }^{21}$ Sanabria said neither he nor his wife was ever charged with a crime, and were arrested for "political reasons" be-

21. Buck, R. (December 25 1979). Argentine couple reunited joyfully here. Seattle Times. Archivo personal de Alicia Partnoy.

92 cause they supported the Isabel Peron regime wich crumbled march 24, 1976. [Sanabria dijo que ni él ni su esposa fueron acusados de un delito, que los arrestaron por "razones políticas" porque apoyaron al régimen de Isabel Perón que se derrumbó el 24 de marzo de 1976.22

As soon as we were arrested, we were blindfolded", separated and taken to an unknown location. They stripped me down and began applying electric shock". For the next four months, he said, he was often and kept blindfolded with his hands tied behind bis back. After that, he was moved to a prison and, though he was tortured, he said: "I was kept under a constant state of psychological pressure". ["Tan pronto como nos arrestaron, nos vendaron los ojos", fueron separados y llevados a un lugar desconocido. "Me desnudaron y comenzaron a aplicar descargas eléctricas”. Durante los siguientes cuatro meses, dijo, estuvo con los ojos vendados y con las manos atadas a la espalda. Después de eso, lo trasladaron a una prisión, donde fue torturado, él mencionó: "Me mantuvieron bajo un estado constante de presión psicológica”].

De esta manera entonces, se observa que en esas primeras notas, si bien el "gancho"23 podía estar en la reunificación de una familia detenida por la dictadura militar, Alicia y Carlos resaltaron la falta de "cargos" en sus detenciones y el carácter político de las mismas. Además, hicieron hincapié en los métodos

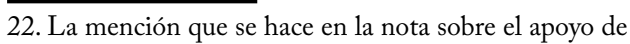
la pareja al régimen de Isabel Perón, recuerda Alicia, fue una interpretación del periodista. Seguramente estuvo ligada al desconocimiento de las diferencias políticas de los sectores ligados al movimiento peronista de aquellos años.

23. "Gancho" en la jerga periodística significa un hecho o personaje atractivo que genera impacto para que la nota obtenga mayor exposición. 
represivos, describiendo el secuestro, la privación sensorial, las torturas, y las condiciones de vida, acciones destacadas en las denuncias de las organizaciones humanitarias (CADHU, 2014 [1977]; Crenzel, 2013; González Tizón, 2016), con las que este grupo de refugiados tenía contactos.

En esas primeras notas, hablaron de su identidad en el peronismo y del carácter político de las detenciones, sin embargo no profundizaron en su militancia. Puede pensarse en una cierta desconfianza aún sobre las posibilidades de escucha en ese país, que parece irse saldando con el paso del tiempo, ya que en las denuncias de los años inmediatamente posteriores (que se tratarán más adelante), Alicia resaltó su participación en la JUP. ${ }^{24}$ En otra de las notas que dieron en esos primeros días, luego de haber llegado a Seattle, esto queda en evidencia, ya que directamente mencionan no haber tenido participación política más allá de discusiones en las aulas de la universidad: "Alicia told U.S. consular officials that neither she nor her husband had ever been a member of a political party and neither had participated political activities other than a few classroom discussions" [Alicia le dijo a los funcionarios consulares de los Estados Unidos que ni ella ni su esposo habían sido miembros de un partido político y ninguno había participado en actividades políticas aparte de algunas discusiones en el aula"]. ${ }^{25}$ De todas maneras, el periodista resalta que el testimonio de Alicia fue a oficiales consulares de los Estados Unidos, con lo que debe pensarse también en estos silencios quién era el receptor.

\footnotetext{
24. De hecho, estos cambios alegan también a la interpretación que se está intentando demostrar, fue encontrando al poco tiempo la confianza como para poder expresarse acerca de su militancia.
}

25. Argentinian describes anti-Semitism (January 10 1980). The Jewish Transcript, p. 12.
Como han trabajado Michael Pollak y Natalie Heinrich en sus estudios sobre mujeres sobrevivientes de campos de concentración nazi, el testimonio no depende sólo de la voluntad de comunicar, sino también y sobre todo de los marcos sociales que lo vuelven comunicable (2006 [1986], p. 56). Las formas de solicitación del relato lo condicionan, existiendo en cada una de las instancias de producción testimonial distintas estructuras que tienen injerencia en su producción. Al analizar el habla es indispensable abordar a quién escucha y en este sentido puede ser interpretada cierta desconfianza aún en las/os argentinos/as entrevistados/as como para exponer la militancia ante los oficiales consulares. Podían poner en riesgo las condiciones de la visa, con lo que optaron por mantener ciertos silencios. ${ }^{26}$

De todos modos, salvo estas excepciones en las que tuvieron que tener "cuidados", el ambiente de escucha no sólo se dio entre pares, sino también desde sectores influyentes en la sociedad, como en los medios de comunicación, las iglesias e instituciones clave del Estado, que fueron interlocutores con cierto desarrollo empático. Como señala Elizabeth Jelin (2002), la capacidad de escuchar requiere de "otros/ as" con una aptitud para interrogar combinada con una capacidad de compasión y empatía (pp. 85-86). En este sentido, encontrar rápidamente una escucha, preguntas, interés por lo que les había ocurrido, fueron factores que facilitaron el habla.

La amplificación de su voz y rostro en las notas periodísticas, pudieron ser una variable en su accionar futuro. Es posible pensar que esa

26. Alicia recuerda que para otorgarles la visa les ponían como condición firmar que no apoyaban la lucha armada. Contacto con Alicia Partnoy por mail, 06 de marzo de 2018. 
exposición en la sociedad funcionó como un elemento más de autoafirmación en el rol de denunciante humanitaria, ya que lo que mostraron las notas a la sociedad no fue sólo su condición de víctima, sino también su palabra y lo que estaba queriendo denunciar.

Este marco de escucha en importantes espacios de la sociedad de Seattle dio la posibilidad para denunciar con ahínco lo que ocurría en el país. En este sentido, los argentinos demostraron una gran cantidad de recursos para esta militancia: la publicación en prensa, campañas de difusión, recolección de firmas; concentraciones, marchas; la oratoria a través de medios de comunicación y en las iglesias; la construcción de vínculos con otros organismos; y gestiones en el Congreso y con el Alcalde de Seattle. $^{27}$

De todos modos, cabe agregar otro matiz sobre esa escucha. Alicia recuerda que hubo en muchos de sus oyentes norteamericanos una predisposición al detalle morboso. Según ella, eso lo hacían para tomar distancia. Es decir, que si bien brindaban atención y se preocupaban, a la vez lo hacían para diferenciarse como estadounidenses de las atrocidades que ocurrían en Argentina. Entonces, aparecía así la empatía necesaria para la escucha pero en paralelo una distancia que incomodaba a quien

27. Lograron a través del trabajo político de denuncia apoyos de sectores del Estado. Como se viene exponiendo, contaron con visas, subsidios y en forma indirecta, a través de las iglesias, con otros recursos. Pero no sólo eso, el mismo alcalde y distintos congresistas asumieron algunos compromisos. Por ejemplo, una acción significativa fue la gestión que hicieron para la visita de la Abuela de Plaza de Mayo María Eugenia Cassinelli de García Iruretagoyena, una de las doce abuelas fundadoras del organismo, familiar de la nieta restituida en el año 2000 Macarena Gelman. Pudieron llevarla a canales de televisión, a radios y lograron una entrevista con el alcalde donde Alicia fue la traductora. hablaba, ya que se planteaba una ajenidad en la que los receptores no tomaban en cuenta la responsabilidad de su país en la instalación de las violencias relatadas. Al notar eso, destaca Alicia que comenzó a hacer hincapié en sus testimonios en el rol de los Estados Unidos en la instalación y consolidación de las dictaduras del Cono Sur. Así es que, con el tiempo, en el discurso de denuncia que iba conformando respecto de lo ocurrido, ingresó también la información sobre la participación de los gobiernos de ese país en los golpes de Estado en América Latina.

Hay otro elemento clave para pensar el habla en este caso, el manejo del idioma. Como relató -con cierto fastidio- en la entrevista que realizamos, desde muy pequeña su familia la había llevado a tomar clases de inglés, alrededor de diez años dedicados a esos estudios, con lo que al llegar lo manejaba en forma dinámica. Estos conocimientos facilitaron la denuncia y la destacaron en el grupo, por eso en el COSPAR decidieron que estuviera como encargada del área de prensa. Como recuerda Antonio: "La que mejor hablaba era Alicia, por eso la pusimos como secretaria de prensa, porque podía hablar con la gente". ${ }^{28}$

En su libro "Venganza de la Manzana”(2009), dice Alicia:

La mujer se zambulle en su memoria en busca de palabras en inglés, idioma que estudiara durante casi diez años. Se niega a abrir un diccionario, señal de su profundo conflicto con el lenguaje de la tierra que no ha elegido como propia (p. 13).

De esta manera, presenta un conflicto, una lengua y una "tierra" que no eligió, pero resalta

28. Entrevista a Antonio Leiva. 
sin embargo, que esos conocimientos le permitieron traducir sus experiencias en distintos formatos: "Su impulso de contar le hace traducir su experiencia al testimonio, el ensayo, la canción, el teatro, el relato. La poesía es su último refugio, el único lugar en que brotan su amargura y su bronca" (p. 13). Entonces, como mencionan las/os protagonistas, el conocimiento sobre el lenguaje fue una herramienta clave en ese primer año de exilio. Resultó así para la denuncia, pero también para ratificar el lugar destacado en el grupo, siendo uno de los nexos principales con la sociedad.

Un último elemento importante para pensar en las condiciones de posibilidad para el habla, es que este grupo tuvo un gran nivel de autodeterminación sobre el qué decir y cómo. Los/ as exiliados/as en Seattle comenzaron a tener contactos con organizaciones de derechos humanos de Argentina y del exterior ya en esos primeros meses de arribo y de conformación del COSPAR, estos vínculos resultaron muy importantes para organizar las acciones políticas anti-dictatoriales. No obstante, la relativa lejanía de la ciudad y la falta de trabajo previo de argentinos allí les permitieron organizarse con relativa autonomía.

En este sentido, a pesar de seguir relacionados/as a las organizaciones revolucionarias a las que algunos pertenecían, decidieron tomar muchas de las consignas de los organismos de derechos humanos asentados en Argentina y en el exilio, $y$ a su vez distanciarse de otras posturas que en estos mismos espacios circulaban, por ejemplo valorando los testimonios de los/ as sobrevivientes de CCD en un contexto de debate. Como se mencionó en la introducción, en octubre de 1979 se había producido la pre- sentación de las sobrevivientes de la ESMA en París, hecho que generó repercusión sobre la legitimidad de esos testimonios -y de quiénes testimoniaban (Franco, 2008, pp. 157-158). Antonio recuerda que esos debates también se dieron en los Estados Unidos. Durante enero de 1980, representantes de las congregaciones de argentinos de ese país y de Canadá, se reunieron durante tres días en Washington para establecer redes de cooperación y acción. La cuestión de qué hacer con los testimonios de los/as sobrevivientes fue tratada y según él, a pesar de que generó peleas con algunos sectores, la mayoría estuvo de acuerdo con que debían difundirse. Por la información que tenía Alicia y por haber experimentado en carne propia la desaparición forzada, su testimonio y su rol en la denuncia fueron legitimados. Era una de las pocas personas que mencionaba elementos de la represión clandestina en la Zona $\mathrm{V}$, tenía datos de las desapariciones en el CCD la "Escuelita", de asesinatos de compañeros/as y de la apropiación de dos bebés por parte del aparato represor.

Entonces, lejos de sentir hostilidad o estigmatizaciones, como se mencionó que ocurrió con otros casos de sobrevivientes, la experiencia de Alicia, muestra cómo las estructuras y los lazos de solidaridad en los que se insertó, sumado a una sociedad permeable a la denuncia, permitieron el desarrollo de un ambiente desde el cual afrontar los efectos de la represión a través de una posición activa, en la militancia contra la dictadura. En estos espacios y tramas vinculares se vio expuesta a una interpelación relativamente empática en la que su rol en la denuncia fue reconocido y legitimado. 


\section{Alicia en el exilio, Washington: nuevos y viejos lazos, y el testimonio escrito}

En enero de 1981, a poco más de un año de haber llegado a Seattle, en el grupo de exiliados/as sintieron que estaban encontrando límites para la difusión, ya que creían haber saturado los espacios en los que podían actuar. De este modo, Alicia y Antonio decidieron ir a la capital administrativa del país, Washington, pensando que allí tendrían mayor visibilidad y resonancia las denuncias. En la entrevista que realizamos con Alicia aparecieron algunos de los motivos sobre por qué viajaron. Uno de ellos fue el recién mencionado, la saturación de los espacios para actuar. Otro, el hecho de que ella era la única que hablaba inglés en forma fluida. En este sentido, nuevamente el conocimiento del lenguaje aparece como un elemento clave. Otra variable más que debe ser señalada, en consonancia con lo que se viene trabajando hasta aquí, es que la pareja tuvo nuevamente estructuras en dónde insertarse.

En Washington estaba Juan Méndez, abogado, también ex prisionero político de la última dictadura argentina y un muy activo defensor de los derechos humanos en los Estados Unidos..$^{29}$ Juan había sido compañero de prisión de Antonio y venían teniendo contactos desde antes de que éste último saliera del país con la "opción". Los invitó a ir, ya que había mucho "trabajo para hacer alli", él mismo les brindó hospedaje en su casa. Alicia y Antonio

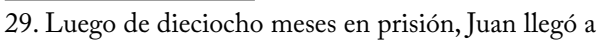
los Estados Unidos expulsado de Argentina a fines de 1977. Tras un año trabajando en la ayuda a migrantes junto a una Iglesia de Illinois, se radicó en Washington. En esta ciudad formó parte del Comité de Abogados por los Derechos Civiles hasta 1982, cuando comenzó un periodo de casi 15 años como referente en Human Rights Watch.

96 continuarían militando desde el COSPAR, vinculándose además a una agrupación referenciada por Juan que hacía trabajos de investigación sobre las violaciones a los derechos humanos y de lobby ante sectores del Estado y organismos internacionales. ${ }^{30}$

En la capital, estos argentinos encontraron nuevamente una red de solidaridades. Luego de vivir alrededor de un mes en el hogar de Juan, junto a su familia, pudieron conseguir un lugar proveído por sectores ligados al cristianismo revolucionario, "Casa Tabor". Allí permanecieron durante otro mes, conociendo en ese tiempo a alrededor de trescientas personas de otros países del continente con problemáticas similares, entre ellas a la sobreviviente guatemalteca Rigoberta Menchú. Al poco tiempo, se trasladaron al hogar de un párroco norteamericano, Phil Wheaton. ${ }^{31}$ Finalmente, luego de que ambos estuvieron en una mejor posición económica pudieron alquilar un departamento. A través de los contactos mencionados, Alicia comenzó a trabajar como recepcionista para la Sección Intereses de Cuba, en la Embajada de Checoslovaquia. El marco de lucha se amplificó a una búsqueda de solidaridad con otros países de América Latina: guatemaltecos, panameños, nicaragüenses, salvadoreños, granadinos y dominicanos, que en esos momentos también estaban en conflictos, pero siendo central la denuncia de lo que ocurrió

30. El trabajo de estos argentinos no tenía difusión, sino que era de acción a través de la construcción de relaciones con congresistas y organismos internacionales, como la ONU y el Banco Interamericano de Desarrollo (BID). Entre estas relaciones fue muy importante la conexión con Amnistía Internacional. Estando en Seattle, Alicia comenzó a dar charlas en actividades de AI, algo que se intensificó durante el periodo en Washington.

31. Este párroco era referente de las luchas contra las dictaduras de América Latina, había sido perseguido por la dictadura de Trujillo en República Dominicana. 
con sus compañeros/as en la "Escuelita". Esta "plurinacionalidad humanitaria", como se verá, permitió aprendizajes y nuevas herramientas para la militancia anti-dictatorial.

En Washington las prácticas de denuncias agregaron otras vías y formatos a los producidos en Seattle, no obstante la "narrativa humanitaria" continuó siendo central. Como han mencionado distintos/as historiadores/ as, durante este periodo se produjo una transición entre una narrativa basada en conceptos de denuncia de la izquierda revolucionaria a una centrada en la de la defensa de derechos humanos universales (Franco, 2008; Jensen, 2010). En el caso de Alicia, esta incorporación es observable en un testimonio escrito que presentó ante organismos internacionales que tenían sede en la capital.

Este documento tiene fecha de abril de 1981, a pocos meses de haber llegado a Washington y consta de varios apartados. En él se detalla su caso, el de su ex esposo y el de los/as compañeros/as con los que compartió cautiverio. Si bien menciona su paso por los distintos penales por donde transitó como presa política y su salida al exilio, la intención del texto es la denuncia de su detención junto a la de otros/ as represaliados/as en el CCD la "Escuelita". Este dato es importante porque permite pensar en la centralidad de la desaparición forzada en relación a otras experiencias represivas en ese contexto de lucha contra la dictadura y la influencia que esta tuvo en la producción testimonial de Alicia como sobreviviente. Nuevamente, citando a Pollak (2006 [1986]), las formas de solicitación del testimonio lo condicionan. Si bien en este caso la propuesta de escribir surgió de ella, lo hizo en un formato y un lenguaje determinado.
En el apartado de "presentación" pueden leerse los objetivos de Alicia. Entre ellos resalta el de sumar su relato a los reclamos que llevaban adelante los organismos de derechos humanos por el esclarecimiento de la situación de los desaparecidos, la aparición con vida de estos y el juzgamiento y castigo a los culpables. En relación a esto último, presenta su texto como "una prueba más":

Este testimonio es una prueba más de la existencia de detenidos desaparecidos en Argentina y de la responsabilidad total que cabe a la Junta Militar en la realización de crímenes contra la humanidad.

Me uno al pedido de los familiares de las víctimas y del pueblo de mi país, que hoy reclaman el total esclarecimiento de la situación de los detenidos desaparecidos: Aparición con vida de los detenidos desaparecidos. Aparición de los niños secuestrados $\mathrm{y}$ nacidos en cautiverio. Juzgamiento y castigo de los culpables. Responsabilizo al Gobierno Militar de Argentina por cualquier represalia que se tome sobre las personas o los bienes de mi familia que viven en el país. Me constituyo en testigo de cargo y me responsabilizo por todo lo expuesto en este testimonio. Estoy dispuesta a declarar ante cualquier organismo que investigue la violación de los derechos humanos en mi país. ${ }^{32}$

Es interesante la selección de palabras que realiza: "prueba", "responsabilidad", "crímenes contra la humanidad", "víctimas", "detenidos desaparecidos", "aparición con vida”, "juzgamiento y castigo a los culpables" y "testigo de cargo”. Como señala Emilio Crenzel (2013), las redes trasnacionales proveyeron a las/los

32. Partnoy, A. (abril, 1981). Testimonio sobre el campo de concentración la Escuelita. Washington. Recuperado de Tribunal Oral Federal en lo Criminal No 1 de Bahía Blanca, Secretaría de Derechos Humanos, Bahía Blanca. 
denunciantes de un léxico específico para ejercer sus demandas (pp. 76-77). En este fragmento se refleja, por un lado, esa circulación y el manejo de algunas de las consignas empleadas por los organismos de derechos humanos nacionales y del exilio; por otro, la utilización de ciertos conceptos ligados al ámbito jurídico, de hecho es llamativo cómo Alicia hace referencia a su posible "constitución" como "testigo de cargo".

La historiadora Silvina Jensen (2017) destaca que en el periodo que va entre 1979 y 1981 los distintos espacios que luchaban contra la dictadura argentina a nivel transnacional se propusieron confrontarla apelando a la vía jurídica. Los organismos (CADHU, Federación Latinoamericana de Asociaciones de Familiares de Detenidos-Desaparecidos/FEDEFAM, Comisión de Solidaridad con Familiares de Desaparecidos en Argentina/COSOFAM, etc.), accionaron y debatieron sobre la posibilidad de encontrar justicia, llegando incluso a imaginar un "Núremberg" argentino. En ese sentido, diagramaron posibles estrategias para tipificar la desaparición forzada como crimen contra la humanidad (Jensen, 2017, pp. 2425). La autora muestra así que las estrategias ligadas a la idea de juzgar los crímenes dictatoriales fueron previas al colapso post Guerra de Malvinas y al cambio de gobierno de 1983.

La producción testimonial de Alicia a través del escrito de abril puede pensarse también en este horizonte de expectativas. Allí se posiciona explícitamente en el rol de testigo y "dispuesta a declarar ante cualquier organismo que investigue". Durante ese año y el siguiente, presentaría este documento en la Organización de las Naciones Unidas (en adelante, ONU), en la Organización de los Estados Americanos (en adelante, OEA), lo difundiría a través de Amnistía Internacional (en adelante, AI), y también lo enviaría a la Argentina a distintos organismos de derechos humanos. ${ }^{33}$

Como se adelantó, también fue importante en el contexto de producción de este testimonio el contacto con víctimas de otras dictaduras de América Latina. Muchas de estas personas estaban empleando la denuncia ante los organismos internacionales como modo de acción. Según el diario El Día de México, entre julio y agosto de 1981 fueron presentadas en la sede de Ginebra de la ONU alrededor de 30.000 denuncias por violaciones a los derechos humanos en distintos países -Argentina, Paraguay, El Salvador, Nicaragua, Afganistán, Irlanda y Turquía. ${ }^{34}$ Como Alicia recuerda en la entrevista que realizamos, cuando llegaron a Washington encontraron que muchos de los/ as refugiados/as latinoamericanos/as con los/ as que entablaron relaciones estaban utilizando esos canales para denunciar a sus dictaduras.

Otro escrito de Alicia que expone la relevancia que tuvo en ese momento la idea de aportar a una estrategia jurídica, es una carta enviada a la Argentina el 4 de diciembre de 1981 a los padres de Raúl Metz. Raúl, junto a su compañera Graciela Romero, habían compartido con Alicia el cautiverio en la "Escuelita". ${ }^{35}$ Si bien

33. El escrito fue enviado a Madres, Abuelas y al Centro de Estudios Legales y Sociales (CELS). Según recuerda, al regresar a la Argentina durante 1984 se acercó a la Plaza de Mayo a una "ronda" de las Madres, allí varias ya lo habían leído y le realizaron preguntas acerca de las personas que había visto en el CCD.

34. Duffey, A. (13 de agosto 1981). En lo que va del mes han sido presentadas a la ONU 30.000 denuncias de violación de derechos humanos. El Día, s.p. Recuperado de http://www.unla.edu.ar/index.php/archivoperiodistico

35. Ambos militaban en el Partido Revolucionario de los 
Alicia era amiga de la hermana de Graciela, María Elena, el hecho que fuerzas militares se hubieran apropiado del hijo de la pareja fue lo que mantuvo en ella el interés de comunicarse con la familia Metz durante esos años. Al enterarse que ellos habían realizado una denuncia y que además se habían contactado con Abuelas de Plaza de Mayo, decidió escribirles una carta. En el final de la misiva, luego de relatar los episodios vividos con las hermanas Romero y con Raúl en el CCD, dice:

Sé que todo esto que les cuento es muy doloroso, pero creo que es la única forma de seguir avanzando en la búsqueda, contarle todo lo que recuerde (...). Recién en febrero de este año, encontré en una lista de Amnistía Internacional que se había hecho la denuncia y habeas corpus de los casos. De allí saqué las fechas exactas de la desaparición (...). Recién ayer a la noche vi en una carpeta de las Abuelas de Plaza de Mayo el caso denunciado, las fotos, su nombre y dirección y es así que decidí escribirles inmediatamente. Le quiero decir que usted puede publicar la información que doy en esta carta y utilizarla para presentar pruebas a la Justicia. Para lo que necesite, me constituiré en testigo presencial. Quiero que sepa que continuaré denunciando el caso y exigiendo la aparición de los tres y que haré todo lo posible por estos hermanos míos y por esclarecer el caso de María Elena. Mucha, mucha fuerza y valor. Sepa que estoy para lo que necesite, ahora no puedo volver al país porque salí de la cárcel

Trabajadores/Ejército Revolucionario del Pueblo (PRT/ ERP). Fueron secuestrados en Cutral-Có a mediados de diciembre de 1976 y trasladados a la "Escuelita". Hacia fines de enero, Raúl fue transferido y fue lo último que se supo de él. Graciela, por su parte, tuvo a su bebé el 17 de abril, permaneció en cautiverio hasta el 23 de ese mes y luego se la llevaron del CCD. con el derecho de opción, pero tiene en mí una hija más. Con cariño, Alicia. ${ }^{36}$

Si bien este escrito posee características diferentes al enviado a los organismos internacionales, nuevamente aparece la intención de poner su testimonio $-\mathrm{y}$ a ella misma constituida como testigo- a disposición de la Justicia. En esta decisión pudo ser importante el hecho de saber que también las familias Metz y Romero habían utilizado los distintos canales de denuncia tanto produciendo habeas corpus en el Juzgado Federal en lo Criminal No 1 de Bahía Blanca como en Abuelas de Plaza de Mayo. Esta situación la persuadía que su testimonio sería vital en la construcción de pruebas sobre lo ocurrido. ${ }^{37}$

Estos escritos presentados tendrían mucha importancia en el futuro, ya que constituirían testimonios clave en los juicios por los crímenes cometidos en la región comandada por el $\mathrm{V}$ cuerpo del Ejército. Al mismo tiempo resultaron fundamentales para la propia Alicia, porque a través de ellos pudo sistematizar sus recuerdos y ponerlos en palabras. Paula Simón (2016) hace referencia al exilio y a la experiencia concentracionaria como fenómenos de dislocación del sujeto, siendo la escritura una forma de recuperar esa afectación a la identidad, algo que ve logrado en el caso de Alicia Partnoy y su reconocido libro La Escuelita (p. 231). La composición de estos primeros textos de 1981 puede ser pensada también en el mismo sentido, como una forma de recomposición subjetiva, no obstante acompañada por otras

36. Partnoy, A. (04 de diciembre de 1981). Carta de Alicia Partnoy a la familia Metz. Tribunal Oral Federal en lo Criminal No 1 de Bahía Blanca, Secretaria de Derechos Humanos.

37. Con esa carta la familia Metz pudo saber que efectivamente había nacido el niño. 
acciones y enmarcada en ciertas condiciones sociales y políticas que, como se viene demostrando a lo largo del trabajo y como señala la antropóloga Luciana Messina (2012) para el caso del testimonio, estuvieron involucradas en el proceso mismo de su producción (p. 56). En este proceso Alicia, habiendo sobrevivido a los dispositivos represivos de la última dictadura, se fue convirtiendo en testigo y sobreviviente.

\section{Conclusiones}

A través del estudio de caso de Alicia Partnoy en los Estados Unidos (1979-1983), se han analizado distintos factores que resultaron fundamentales en el desarrollo de las condiciones de posibilidad para la exposición pública de una víctima de los espacios de detención clandestina de la última dictadura. En primer lugar, se destacó la inserción de esta protagonista en redes de solidaridad que le permitieron -igual que a varios de los/as argentinos/ as refugiados/as- comenzar a reestructurarse socialmente en el exilio. En su caso, esos lazos fueron clave en aspectos sociales, económicos y políticos, tanto en Seattle como luego en Washington. También, se ha señalado como una variable importante su interacción con una heterogénea audiencia interesada que tuvo la empatía necesaria -no sin algunas tensionespara que se produjera la relación habla/escucha (Jelin, 2002). En este proceso, con los/as compañeros/as, en las iglesias, en los medios, ante funcionarios del Estado, organizaciones de derechos humanos y organismos internacionales, Alicia fue convirtiéndose en una de las referentes en la comunicación del COSPAR, narrando lo que ocurría en Argentina desde su propia historia. Su lugar en las prácticas de denuncia fue legitimado por su grupo de per- tenencia y por una gran parte de los actores sociales con los que interactuó, siendo reconocida como víctima y en un rol determinado en la exposición de los crímenes dictatoriales.

En estas relaciones los/as actores involucrados/ as en las prácticas de denuncia utilizaron un lenguaje en "clave humanitaria" que fue fundamental para la conformación de muchos de los vínculos, y a la vez para el posicionamiento de la víctima como sobreviviente y testigo de la experiencia del CCD. Las redes trasnacionales (Sikkink, 1996) proveyeron a las/os exiliados "de un léxico para ejercer las demandas" en una "narrativa humanitaria" (Crenzel, 2013) que privilegió la denuncia de la desaparición forzada como crimen contra la humanidad. Los escritos de Alicia en Washington durante 1981 exponen su accionar en esa trama discursiva. Si bien en ellos no dejó de mencionar su militancia en la JUP y la experiencia de la prisión y del exilio como parte de las políticas represivas que debió padecer, en un contexto en el que la búsqueda de sanciones a la dictadura por las violaciones a los derechos humanos en un sentido jurídico-legal estaba en el horizonte de expectativas de algunas de las organizaciones exiliares (Jensen, 2017), esta protagonista dio centralidad a la narración de la experiencia de la desaparición en el CCD "La Escuelita", reconociéndose $-\mathrm{y}$ siendo reconocida- como sobreviviente y en el rol de dar testimonio para la búsqueda de justicia.

En este sentido, el recorrido por la historia del exilio de Alicia permite exponer cómo en ese contexto se produjo esta temprana asociación entre ambas categorías, sobreviviente y testigo, que durante mediados de 1980 en Argentina, con la Comisión Nacional sobre la Desaparición de Personas (CONADEP) y los primeros juicios, se convertirá en una de las represen- 
taciones más generalizadas para hacer referencia a las personas que salieron con vida de los CCD (González Tizón, 2016). En su caso, como sucedió en otras experiencias, la asociación entre sobreviviente y el rol de dar testimonio, centrando la narrativa de la experiencia en la etapa de desaparición, pasó a formar parte de su identidad. Este posicionamiento lo manifestó ella misma unos pocos años más tarde en su libro La Escuelita, donde haciendo referencia a esos primeros tiempos en Seattle y Washington, señaló que por su condición de sobreviviente sintió que tenía el deber de dar testimonio de lo ocurrido (Partnoy, 2006 [1986], p. 13).

\author{
$\propto \tilde{e} \propto$ \\ Recibido: 16-11-2018 \\ Aceptado: 03-05-2019 \\ Publicado: 04-12 -2019
}




\section{Referencias bibliográficas}

Águila, G., Luciani, L., Seminara, L., y Viano, C. (Comps.). (2018). La historia reciente en Argentina. Balances de una historiografía pionera en América Latina. Buenos Aires: Imago Mundi.

Ayala, M. (2013). Reaparecer en el exilio: experiencias de argentinos sobrevivientes de centros clandestinos de detención en Venezuela (1979-1984). Ponencia presentada en Jornadas de la Asociación Argentina de Historia de las Relaciones Internacionales, Buenos Aires, Argentina.

Calandra, B. (2006). L'America della solidarietá L'accoglienza dei rifugiati cileni e argentini negli Stati Uniti (1973-1983). Roma: Edizioni Nuova Cultura.

Comisión Argentina de Derechos Humanos (2014 [1977]). Argentina: Proceso al Genocidio. Buenos Aires: Colihue.

Crenzel, E. (2013). Los derechos humanos, una verdad evidente de la democracia en la Argentina. Estudios, (29), 73-91. Recuperado de https://revistas.unc.edu.ar/index.php/restudios/article/view/5340

D’Antonio, D. (2010). Derechos humanos y estrategias de la oposición bajo la dictadura militar argentina, Tensões Mundiais, World Tensions, 6(11), 153-168. Recuperado de https://revistas.uece.br/index.php/ tensoesmundiais/article/view/656

D’Antonio, D. (2017). La prisión en los '70: Historia, género y politica. Buenos Aires: Biblos.

Franco, M. (2008). El exilio: argentinos en Francia durante la dictadura. Buenos Aires: Siglo XXI.

Franco, M. y Lvovich, D. (2017). Historia Reciente: apuntes sobre un campo de investigación en expansión. Boletin del Instituto de Historia Argentina y Americana “Dr. Emilio Ravignani”, (47), 190-217. Recuperado de http://ppct.caicyt.gov.ar/index.php/ravignani/article/view/11091/pdf_1

González Tizón, R. (2016). Cada voz que se alce puede salvar una vida en Argentina: la producción testimonial de los sobrevivientes de los Centros Clandestinos de Detención en el marco de la Comisión Argentina por los Derechos Humanos (1979-1983). Papeles de Trabajo, 10 (17), 162-183. Recuperado de http://www.unsam.edu.ar/revistasacademicas/index.php/papdetrab/search/authors/view?firstName $=$ Rodrigo \&middleName $=\&$ lastName $=$ Gonz\%C3\%A1lez\%20Tiz\%C3\%B3n\&affiliation $=$ Institu to\%20de\%20Investigaciones\%20Gino\%20Germani\%20-\%20CONICET\&country=AR

González Tizón, R. (2018). Militancia bumanitaria y testimonio. Los sobrevivientes de "El Vesubio" y la denuncia de los crimenes de la última dictadura (1978-2016) (Tesis doctoral inédita). Instituto de Altos Estudios Sociales, Buenos Aires, Argentina.

Jelin, E. (2002). Los trabajos de la Memoria. Buenos Aires: Siglo XXI.

Jensen, S. (2017). Los exiliados argentinos y las luchas por la Justicia. Estudios, (38), 13-30. Recuperado de https://revistas.unc.edu.ar/index.php/restudios/article/view/19126 
Jensen, S. (2018). La historiografía del último exilio político argentino. Itinerarios y desafíos. En G. Águila, L. Luciani, L. Seminara y C. Viano (Comps.), La historia reciente en Argentina. Balances de una historiografía pionera en América Latina. Buenos Aires: Imago Mundi.

Jensen, S. y Lastra, S. (2016). Formas de exilio y prácticas represivas en la Argentina reciente (1974-1985). En G. Águila, S. Garaño, P. Scatizza (Coords.), Represión estatal y violencia paraestatal en la historia reciente argentina: Nuevos abordajes a 40 años del golpe de Estado (pp. 155-185). La Plata: Universidad Nacional de La Plata.

Kordon, D., Edelman, L., Lagos, D., Bozzolo, R., Nicoletti, E., Siaky, D., Kandel, E., Hoste, M., Bonano, O., Kersner, D. (1986). Efectos psicológicos de la represión politica. Buenos Aires: Sudamericana.

Lampasona, J. (2017). Entre la desaparición y la (re-)aparición. Un análisis de las inscripciones biográficas de la experiencia de la (propia) desaparición en los sobrevivientes de los Centros Clandestinos de Detención en la Argentina (Tesis doctoral inédita). Universidad de Buenos Aires, Buenos Aires, Argentina.

Messina, L. (2012). Reflexiones en torno a la práctica testimonial sobre la experiencia concentracionaria en Argentina. Sociedad y Economia, (23), 37-58. Recuperado de http://sociedadyeconomia.univalle.edu.co/ index.php/sociedad_y_economia/article/view/3978

Partnoy, A. (2006). La Escuelita: Relatos testimoniales. Buenos Aires: La Bohemia.

Partnoy, A. (2009). Venganza de la manzana. Bahía Blanca: Hemisferio Derecho.

Pollak, M. y Heinrich, N. (2006). El testimonio. En M. Pollak, Memoria, olvido, silencio. La producción social de identidades frente a situaciones limite (pp. 53-112). La Plata: Ediciones Al Margen.

Sikkink, K. (1996). La red internacional de derechos humanos en América Latina: surgimiento, evolución y efectividad. En E. Jelin, E. y E. Hershberg, Construyendo la democracia: Derechos bumanos, ciudadania y sociedad en América Latina (pp. 71-96). Caracas: Nueva Sociedad.

Simón, P. (2016). Narraciones dislocadas: el exilio y el campo de concentración, dos formas de la violencia en la literatura testimonial argentina y española. Kamchatka, Revista de análisis cultural, (8), 223-237. Recuperado de https://ojs.uv.es/index.php/kamchatka/article/view/9444/8944 